\title{
Axial compressor fouling detection for gas turbine driven gas compression unit
}

\author{
Nurlan Batayev \\ Department of Automation and Control, Satbayev University, Kazakhstan
}

\begin{tabular}{l} 
Article Info \\
\hline Article history: \\
Received Dec 14, 2018 \\
Revised Mar 27, 2019 \\
Accepted Apr 19, 2019 \\
\hline
\end{tabular}

\section{Keywords:}

Axial compressor fouling Centrifugal gas compressor Compressor efficiency Fuel gas specific flow rate Gas turbine

\begin{abstract}
One of the main reasons of the performance degradation of gas turbines is the axial compressor fouling due to air pollutants. Considering the fact that the fouling leads to high consumption of fuel, reducing of the axial compressor's discharge air pressure and increasing of the exhaust temperature, thus designing a compressor degradation detection system will allow prevent such issues. Many gas turbine plants lose power due to dirty axial compressor blades, which can add up to $4 \%$ loss of power. In case of power plants, the power loosing could be observed by less megawatts produced by generator. But in case of gas compression stations the effect of power loosing could not be quickly detected, because there is not direct measurement of the discharge power produced by gas turbine. This article represents technique for detection of gas turbine axial compressor degradation in case of gas turbine driven natural gas compression units. Calculation of the centrifugal gas compressor power performed using proven methodology. Approach for evaluation of the gas turbine performance based on machine learning prediction model is shown. Adequacy of the model has been made to three weeks' operation data of the 10 Megawatt class industrial gas turbine.
\end{abstract}

Copyright $@ 2019$ Institute of Advanced Engineering and Science. All rights reserved.

\section{Corresponding Author:}

Nurlan Batayev,

Department of Automation and Control,

Satbayev University,

22a Satpaev Street, Almaty, Kazakhstan.

Email: n.batayev@zeinetsse.com

\section{INTRODUCTION}

A modern characteristic feature of the world's oil and gas industry is the increasing consumption of natural combustible gases. This is due to the fact that gas is more environmentally friendly and cheaper fuel than gasoline or diesel fuel. Natural gas is increasingly used in gas vehicles, at gas power plants, in gas chemistry for the production of large-capacity base products like ethylene and methanol, in metallurgical and other types of industry and housing sectors. As per British Petroleum Statistical Review of World Energy given at Figure 1, natural gas consumption is increasing over the last 50 years. Mining and consumption of natural gas is growing at a higher rate than comparable indicators for oil [1]. In this regard, the role of gas pipelines is significant, where the main element is a gas compression station. Gas Compression station stationary or mobile installation, designed to receive compressed gases with further transportation to the places of use. The technological scheme of the compressor station consists of a gas cleaning systems, compressor trains, gas cooling installations, etc. Mainly, centrifugal compressor is driven by gas turbine.

Gas turbines as a result of the long operating hours are subjected to various damages, and their performance may deteriorate over time due to many reasons such as clogging, corrosion, erosion, thermal distortion, external (or internal) object damage and blockage of fuel injectors [2]. The consequences of this performance degradation can be increased fuel consumption, reduced component efficiency and complete destruction of the gas turbine. Additional effects of dirty compressor blades are higher turbulence levels, 
reduced cross section of flow, lower compressor outlet pressures, higher compressor and turbine outlet temperatures [3]. Consequently, increasing the efficiency and service life of engine components, on the one hand, and maintaining system stability, on the other hand, are considered among the main reasons for developing fault detection and identification systems.

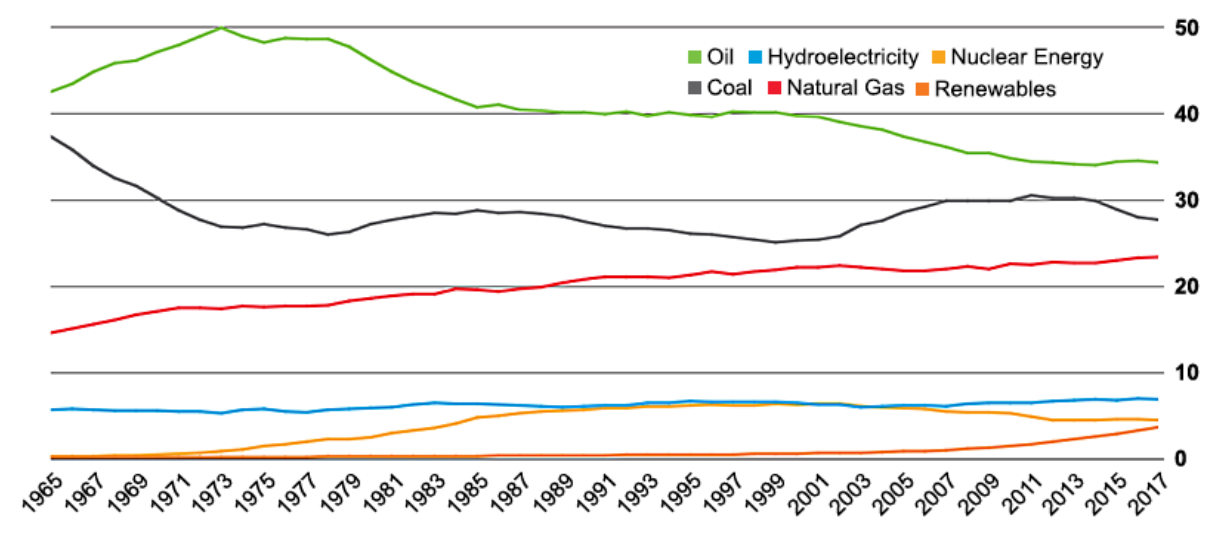

Figure 1. Shares of global energy consumption by fuel in percentage [1]

Over the last decades different methodic for gas turbine fault detection have been proposed. In [4] fault detection system described for an industrial two-shaft gas turbine in case of full and partial loads. Most of the modern gas turbine prognostic programs are consists of four technical processes: Data Acquisition, Health Indicator construction, Health Stage Division and Remaining Useful Life (RUL) prediction. Over the recent years, many researches have made an excellent overview on the RUL prediction. Some articles widely cover a systematic review of all four processes [5]. A systematic observation of recently developed gas turbine diagnostic, performance monitoring and prognostic techniques reviewed [6]. Many studies have been performed in field of fault detection [7-12] and diagnostic of gas turbines [13-19]. Studies given in [20-22] are using numerical simulation techniques for defining a fault.

A number of researches have made an investigation related to axial compressor degradation. The main reasons of performance degradation for industrial gas turbines are erosion, corrosion, fouling and some internal damages. Mainly, degradation is caused by erosion and fouling due to contaminants in the air [23]. Erosion formatted by hard particles in the air larger than $10 \mu \mathrm{m}$ and these particles should be eliminated by filtration system. Soft particles smaller than 2 to 10 microns causes compressor fouling, common examples of such particles are smoke, carbon, oil mists, sea salts [24]. Compressor fouling can be eliminated by proper air filtration system and off-line compressor washing. The effectiveness of the compressor washing is significantly high [25].

To evaluate gas turbine performance degradation, the performance change characteristics should be considered. Industrial gas turbines running under various loads and their performance depends on factors such as turbine design, operating mode and ambient conditions. For instance, the performance is higher when outside ambient temperature is lower. Therefore, for proper evaluation, gas turbine performance should be corrected for comparison under a fixed reference conditions like ISO or compared with the expected performance. Usually, there are 2 categories of turbine degradation: mechanical and performance. Mechanical degradation depends on many mechanical factors, for example failures in lube oil system, vibration, noise, etc. Performance degradation can be divided into two types: recoverable and nonrecoverable. Recoverable degradation can be recovered by proper maintenance actions such as offline water wash. Non-recoverable degradation recovered during the outages and overhaul by replacing mechanical parts [26].

In this articles proposed technique for detection of gas turbine axial compressor degradation in case of gas turbine driven natural gas compression units. Calculation of the centrifugal gas compressor shaft power and efficiency related parameters performed. Approach for evaluation of the gas turbine performance based on machine learning prediction model is shown. Adequacy of the model has been made to three weeks' operation data.

The remaining of this paper is organized as follows. Section 2 discusses about research methodology, modeling and algorithm. In Section 3 described the results. Conclusions are drawn in Section 4. 


\section{RESEARCH METHOD}

\subsection{Gas Turbine}

Gas turbine is a blade machine, where the energy of compressed and heated gas is converted into mechanical work on the shaft. The main structural elements of the typical gas turbine are air intake section, axial compressor, combustion chamber and exhaust sections.

Ambient air intakes preliminary cleaned in air filters. In compressor section the pressure and temperature of the air increasing. Further in combustion chamber air is mixed with fuel and burned, the temperature reaches the peak values. Expanding gases rotates turbine blades and creates shaft power. The object of analysis is a $10 \mathrm{MW}$ industrial gas turbine and gas compressor at the shaft end. The structure of the process gas turbine and compressor is given at Figure 2.

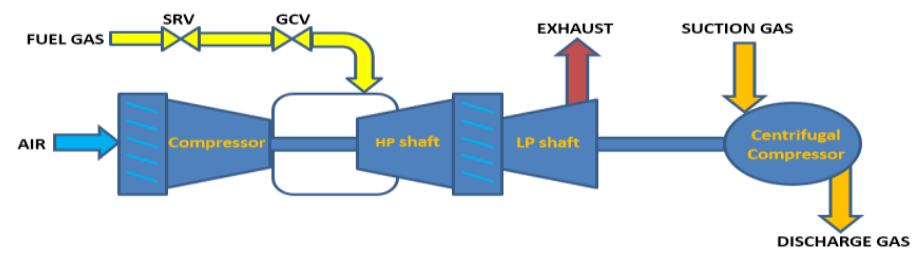

Figure 2. Gas turbine and centrifugal gas compressor layout schematic

\subsection{Measured Data}

Measured data over a period of 3 weeks (January 2018) were obtained from one of compressor stations, located in the Republic of Kazakhstan. The data represents plant operation at a part load. The data have been collected with a frequency 30 seconds ( 2 points per minute). The parameters include ambient data (temperature, pressure), gas path pressures ant temperatures, fuel gas properties (flow and temperature). During this period the compressor's suction gas temperatures varied from -10 to +2 , and pressures varied from 5.4 $\mathrm{MPa}$ to 5.8 $\mathrm{MPa}$. A few times shutdown of the unit has been taken a place. The variations of the temperatures and pressures are shown through Figure 3 and Figure 4.
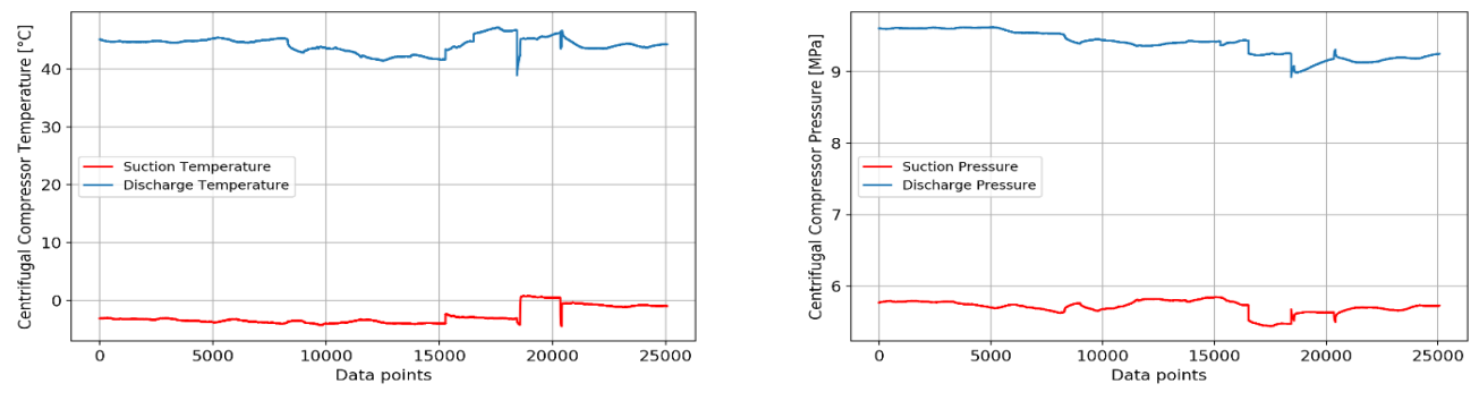

Figure 3. Centrifugal gas compressor's temperatures (left) and pressures (right) variations for the measured period of time
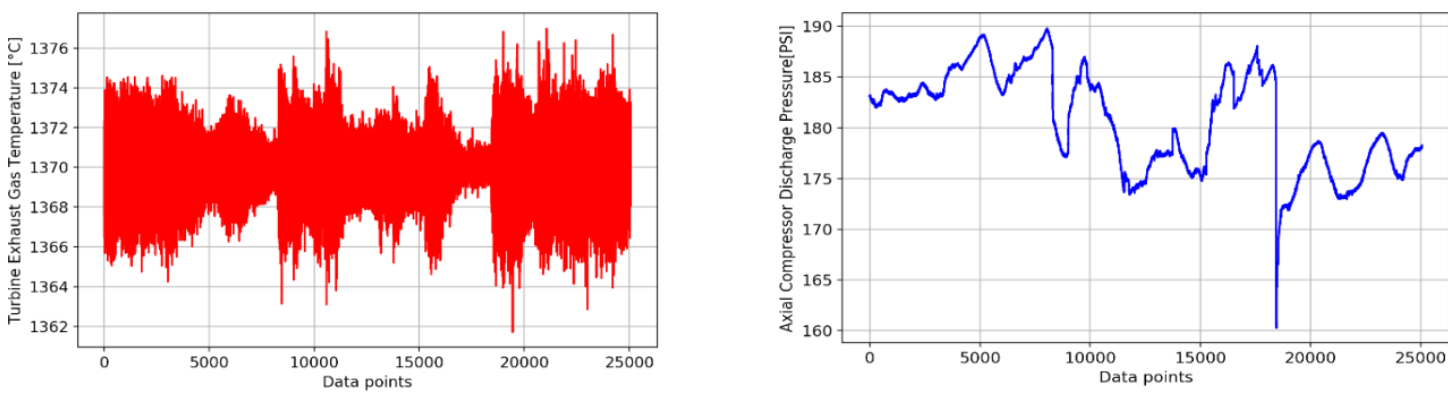

Figure 4. Gas turbine EGT (left) and axial compressor's discharge pressure (right) variations for the measured period of time 


\subsection{Fauling Detection Algorithm}

As known, the main application of gas turbine engines in industry are gas compression and electric power stations, where the turbine drives a centrifugal compressor and an electric generator respectively. In both cases, over the time, the axial compressor of the gas turbine degrades due to the presence in atmospheric air of dust particles, salt, etc. In the case of electric generator, the drop in power can be seen by the output power, usually measured in megawatts per hour.

For example, if in the initial state with the maximum load of the turbine, the output on the generator was $45 \mathrm{MW}$, then due to the degradation over the time, the same turbine at the maximum load can produce $42 \mathrm{MW}$, i.e. it can be seen that the turbine at its maximum began to produce less megawatts.

In case of a centrifugal compressor, there is no explicit quantitative measure of the output power. In this regard, in the framework of this article is given a method for finding the degradation of the turbine's axial compressor.

This method is based on a calculation of the centrifugal compressor's power, determining the specific fuel gas consumption, a model based on machine learning methods, which determines the dependence of the specific fuel gas consumption on the parameters of a gas turbine. The main parameters of the turbine, which correlate with the specific consumption of fuel gas, are speed, axial compressor's discharge pressure, exhaust temperature.

The block structure of the calculations is given at Figure 5. First step is to read the input parameters, which are required for calculation of the centrifugal compressor's pseudo isentropic index, compressibility, polytrophic temperature index, internal power and specific fuel gas consumption. Next step is to train the model, where the target parameter is specific fuel gas consumption and features are gas turbine shafts speed, exhaust gas temperature, axial compressors discharge pressure. When the model is trained and tested, it can give prediction for specific fuel gas consumption, we compare the predicted and current calculated value, and if the relationship is higher than $\mathrm{k}$, we can decide that turbine efficiency become lower and water wash is required. The setpoint k can vary for different types of gas turbines, in our case we have used $\mathrm{k}=2 \%$.

Centrifugal compressor's power is a function of difference of suction and discharge temperatures, average compressibility, mass gas flow and can be defined by (1).

$$
N_{c}=4 \cdot \frac{k}{k-1} \cdot Z_{\text {avr }} \cdot R \cdot\left(T_{\text {out }}-T_{\text {in }}\right) \cdot G_{c}
$$

Where, $\frac{k}{k-1}$ - pseudo isentropic index, which is defined by (2).

$$
\frac{k}{k-1}=4.16+0.0041 \cdot\left(t_{\text {avr }}-10\right)+3.93 \cdot\left(\Delta_{\text {air }}-0.55\right)+5 \cdot\left(m_{T}-0.3\right)
$$

And $m_{T}$ is the polytrophic temperature index, defined by (3).

$$
m_{T}=\frac{\lg \frac{T_{\text {out }}}{T_{\text {in }}}}{\lg \frac{P_{\text {out }}}{P_{\text {in }}}}
$$

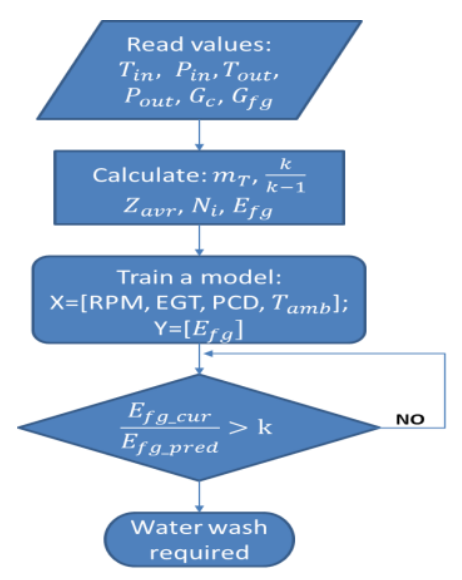

Figure 5. Sequence for defining the axial compressor degradation 
The detailed description of the parameters calculation is given in the methodology for assessing the energy efficiency of gas transmission facilities and systems [27]. Further, the calculated power value is used in determining the specific gas flow rate, which is the relation of fuel gas mass flow rate to the calculated power.

$$
E_{\text {fuel gas }}=\frac{G_{f g}}{N_{c}}
$$

\section{RESULTS AND DISCUSSION}

Within this article, a method for determining the degree of turbine degradation is proposed. In comparison with other modern methods, the one is not so complicated and based on calculations of the centrifugal compressor internal power with further implementation of machine learning model.

As the specific fuel gas flow rate have been defined, the next step is creation of model based on machine learning methods. Actual data sometimes contains gaps, not a number and empty values, i.e. data should be properly preprocessed in order to eliminate such issues. To assess the effectiveness of the model the data have been split into two parts - training and test datasets. Training data used to train the model, and for evaluation of model correctness on new data the test dataset is required. The data split is done in a ratio of 70/30, where $70 \%$ is a training part and $30 \%$ is a test part [28-29].

As known, supervised training assumes the presence of the target attribute and the model is built on the basis of the object response pair. Among a number of machine learning models, Linear Regression, LassoCV and RidgeCV have been selected [30]. These methods are belong to a statistical method of studying the effect of one or independent variables $X_{n}$ on the dependent parameter $Y$. Considering the parameter vector $X^{T}=X_{1}, X_{2}, \ldots, X_{n}$, the target parameter $Y$ is forecasted by the (5).

$$
\hat{Y}=\hat{\beta}_{0}+\sum_{j=1}^{n} X_{j} \hat{\beta}_{0}
$$

Where $\hat{\beta}_{0}$ is displacement. Correctness of the prediction data for validation dataset has been defined by the method of least squares, for which is used minimization of displacement $\beta$ :

$$
\operatorname{RSS}(\beta)=\sum_{j=1}^{n}\left(y_{i}-x_{i}^{T} \beta\right)^{2}
$$

Figure 6 shows the predicted and actual values of the specific value of flow gas based on Linear Regression method. The behavior of predicted curve repeats the actual one for most of the points. The Mean Squared Error is equal to 0.001804579409127899.

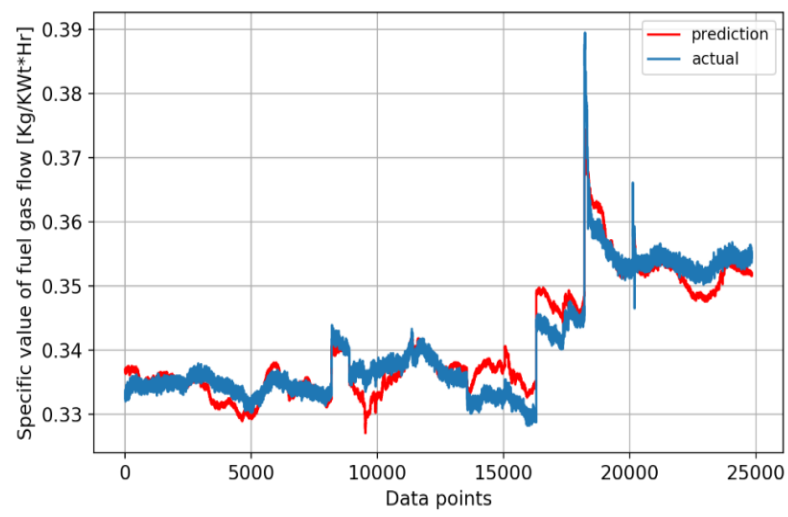

Figure 6. Actual and predicted values of the specific value of fuel gas flow by Linear Regression

LassoCV and RidgeCV methods are gives approximately the same results, the predicted and actual values are shown at Figure 7. The Mean Squared Error for LassoCV is 0.0018035260174060243 , and for RidgeCV is 0.0018045684851681711 . 

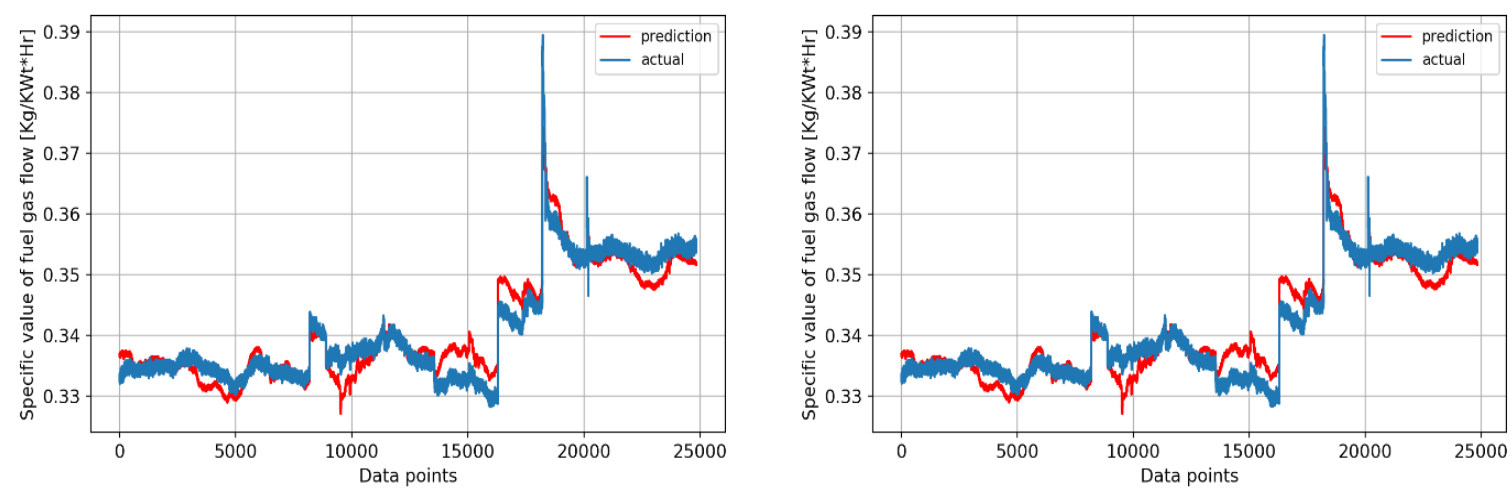

Figure 7. Actual and predicted values of the specific value of fuel gas flow by LassoCV (left) and RidgeCV(right)

\section{CONCLUSION}

On base of obtained data, centrifugal compressor's internal power has been calculated. After defining the internal power, new efficiency parameter - Specific value of fuel gas flow have been defined as a relation between the actual value of fuel gas flow rate to the centrifugal gas compressor's internal power. The parameter shows the relationship between consumed fuel gas and power at the shaft's end. This value gives understanding how consumption of fuel gas depends on gas turbine conditions: increasing of this parameter means that for the same amount of produced power spend more fuel, which can be caused by axial compressor degradation, if there no any other mechanical issues. Short-time period data have been used for testing of the proposed method. Machine learning regression methods performed for creating the prediction model.

\section{ACKNOWLEDGEMENTS}

The author would like to thank "Zeinet\&SSE" LLP for providing all necessary information and supporting the project.

\section{REFERENCES}

[1] British Petroleum, "BP Statistical Review of World Energy 2018," Stat. Rev. World Energy, pp. 1-56, 2018.

[2] T. Engelberth, D. Krawczyk, and A. Verl, "Model-based Method for Condition Monitoring and Diagnosis of Compressors," Procedia CIRP, vol. 72, pp. 1321-1326, 2018. DOI:10.1016/j.procir.2018.03.271.

[3] M. Gera, “Advanced Compressor Cleaning System for Siemens Gas Turbines," Siemens AG, Energy Serv. Div., 2010.

[4] E. Mohammadi and M. Montazeri-Gh, "A Fuzzy-based Gas Turbine Fault Detection and Identification System for Full and Part-Load Performance Deterioration," Aerosp. Sci. Technol., vol. 46, pp. 82-93, 2015. DOI:10.1016/j.ast.2015.07.002.

[5] Y. Lei, N. Li, L. Guo, N. Li, T. Yan, and J. Lin, "Machinery Health Prognostics: A Systematic Review from Data Acquisition to RUL Prediction," Mech. Syst. Signal Process., vol. 104, pp. 799-834, 2018. DOI:10.1016/j.ymssp.2017.11.016.

[6] M. Tahan, E. Tsoutsanis, M. Muhammad, and Z. A. Abdul Karim, "Performance-based Health Monitoring, Diagnostics and Prognostics for Condition-based Maintenance of Gas Turbines: A Review," Appl. Energy, vol. 198, pp. 122-144, 2017. DOI:10.1016/j.apenergy.2017.04.048.

[7] L. Pattanayak, "Thermodynamic Modeling and Exergy Analysis of Gas Turbine Cycle for Different Boundary Conditions," Int. J. Power Electron. Drive Syst., vol. 6, no. 2, pp. 205-215, 2015. DOI:10.11591/ijpeds.v6.i2. pp 205-215.

[8] N. Mahmod and N. A. Wahab, "Fouling Prediction Using Neural Network Model for Membrane Bioreactor System," Indones. J. Electr. Eng. Comput. Sci., vol. 6, no. 1, pp. 200-206, 2017. DOI:10.11591/ijeecs.v6.i1. pp 200-206.

[9] S. K. Mishra, S. C. Swain, and L. N. Tripathy, "Fault Detection \& Classification in UPFC Integrated Transmission Line using DWT," Int. J. Power Electron. Drive Syst., vol. 8, no. 4, pp. 1793-1803, 2017. DOI:10.11591/ijpeds.v8.i4.pp1793-1803.

[10] K. Bhaskar, S. Sendilvelan, and L. R. Sassykova, "Effect of Premix and Exhaust Gas Recirculation on the Emission Characteristics of Biodiesel Fueled Engine,” News Natl. Acad. Sci. Repub. Kazakhstan, Ser. Geol. Tech. Sci., vol. 2, no. 428 , p. 2019, 2018. 
[11] O. V. Zhirnova, B. A. Suleimenov, A. Z. Toigozhinova, and W. T. Wojcik, "Construction of Mathematical Model the Combustion of Biogas to Reduce Greenhouse Gas Emissions," News Natl. Acad. Sci. Repub. Kazakhstan, Ser. Geol. Tech. Sci., vol. 1, no. 421, pp. 177-185, 2017.

[12] O. V Zhirnova et al., "Diagnosis of Combustion Process Biogas and Gas Power Plants to Reduce Greenhouse Gas Emissions," News Natl. Acad. Sci. Repub. Kazakhstan, Ser. Geol. Tech. Sci., vol. 6, no. 420, pp. 123-135, 2016.

[13] M. Z. Sogut, E. Yalcin, and T. H. Karakoc, "Assessment of Degradation Effects for An Aircraft Engine Considering Exergy Analysis,” Energy, vol. 140, pp. 1417-1426, 2017. DOI:10.1016/j.energy.2017.03.093.

[14] D. P. Xenos, G. M. Kopanos, M. Cicciotti, and N. F. Thornhill, "Operational Optimization of Networks of Compressors Considering Condition-based Maintenance," Comput. Chem. Eng., vol. 84, pp. 117-131, 2016. DOI:10.1016/j.compchemeng.2015.08.008.

[15] D. W. Kang and T. S. Kim, "Model-based Performance Diagnostics of Heavy-Duty Gas Turbines using Compressor Map Adaptation,” Appl. Energy, vol. 212, no. September 2017, pp. 1345-1359, 2018. DOI:10.1016/j.apenergy.2017.12.126.

[16] F. Safiyullah, S. A. Sulaiman, M. Y. Naz, M. S. Jasmani, and S. M. A. Ghazali, "Prediction on Performance Degradation and Maintenance of Centrifugal Gas Compressors using Genetic Programming," Energy, vol. 158, pp. 485-494, 2018. DOI:10.1016/j.energy.2018.06.051.

[17] J. R. Laguna-Camacho et al., "A Study of the Wear Damage on Gas Turbine Blades," Eng. Fail. Anal., vol. 61, pp. 88-99, 2016. DOI:10.1016/j.engfailanal.2015.10.002.

[18] E. L. Ntantis and P. N. Botsaris, "Diagnostic Methods for An Aircraft Engine Performance," J. Eng. Sci. Technol. Rev., vol. 8, no. 4, pp. 64-72, 2015.

[19] W. Al-Busaidi and P. Pilidis, "Modelling of the Non-Reactive Deposits Impact on Centrifugal Compressor Aerothermo Dynamic Performance," Eng. Fail. Anal., vol. 60, pp. 57-85, 2016. DOI:10.1016/j.engfailanal.2015.11.027.

[20] P. T. D. Rompas and J. D. I. Manongko, "A Numerical Modeling for Study Marine Current in the Manado Bay, North Sulawesi," TELKOMNIKA (Telecommunication Computing Electronics and Control., vol. 16, no. 1, p. 18, 2018. DOI:10.12928/telkomnika.v16i1.5919.

[21] N. N. M. Nistah, K. H. Lim, L. Gopal, and F. B. I. Alnaimi, "Coal-Fired Boiler Fault Prediction using Artificial Neural Networks,” Int. J. Electr. Comput. Eng., vol. 8, no. 4, pp. 2486-2493, 2018. DOI:10.11591/ijece.v8i4.pp2486-2493.

[22] M. N. Khoshrodi, M. Jannati, and T. Sutikno, "A Review of Wind Speed Estimation for Wind Turbine Systems Based on Kalman Filter Technique," Int. J. Electr. Comput. Eng., vol. 6, no. 4, pp. 1406-1411, 2016. DOI:10.11591/ijece.v6i4.10735.

[23] D. W. Kang and T. S. Kim, "Model-based Performance Diagnostics of Heavy-Duty Gas Turbines using Compressor Map Adaptation," Appl. Energy, vol. 212, no. December 2017, pp. 1345-1359, 2018. DOI:10.1016/j.apenergy.2017.12.126.

[24] R. Kurz and K. Brun, "Fouling Mechanisms in Axial Compressors," J. Eng. Gas Turbines Power, vol. 134, no. 3, p. 032401, 2012. DOI:10.1115/1.4004403.

[25] B. Maiwada, N. I. Mu 'az, S. Ibrahim, and S. M. Musa, "Impacts of Compressor Fouling on the Performance of Gas Turbine," Int. J. Eng. Sci. Comput., vol. 6, no. 3, pp. 2118-2125, 2016. DOI:10.4010/2016.514.

[26] X. Jiang and C. Foster, "Remote Thermal Performance Monitoring and Diagnostics - Turning Data into Knowledge," Proc. ASME 2013 Power Conf., no. 1, pp. 1-7, 2013.

[27] Gazprom, STO Gazprom 2-3.5-113-2007. "Appraisal Procedure of Power Efficiency of Gas-Transportation Installations Ans Systems". 2007.

[28] N. Batayev and A. Onbayev, "Prediction of Gas Turbine Parameters based on Machine Learning Regression Methods," Proc. 6th Int. Virtual Conf. Adv. Sci. Results, vol. 6, pp. 217-221, 2018. DOI:10.18638/scieconf.2018.6.1.495.

[29] N. Batayev, "Gas Turbine Fault Classification based on Machine Learning Supervised Techniques," in 14th International Conference on Electronics Computer and Computation, ICECCO 2018, 2019. DOI:10.1109/ICECCO.2018.8634719.

[30] A. C. Müller and S. Guido, "Introduction to Machine Learning with Python: A Guide for Data Scientists". O’Reilly, 2016.

\section{BIOGRAPHIES OF AUTHORS}

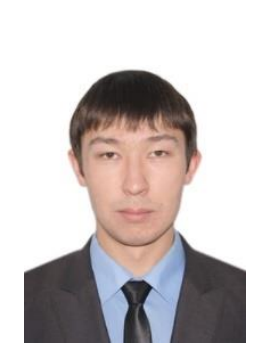

Nurlan Batayev received his Bachelor (Automation and Control) and MSc. Information Systems from Kazakh-British Technical University, Kazakhstan in 2012 and 2014 respectively. He is currently working toward his $\mathrm{PhD}$ in Automation and Control at the Satbayev University, Almaty, Kazakhstan. Working in "Zeinet\&SSE" LLP he has a 7 years' experience in control of the industrial gas turbines, centrifugal gas compressors. His current research interests include fault diagnostic of gas turbines and application of centrifugal gas compressor modeling and control. 